\title{
Morphologic and biochemical changes in the retina and sclera induced by form deprivation high myopia in guinea pigs
}

\author{
Yingxin Zi ${ }^{1,2}$, Yu Deng ${ }^{1,2}$, Jingru Zhao ${ }^{1}$, Meiqi Ji ${ }^{1,2}$, Yali Qin ${ }^{1,2}$, Tingting Deng ${ }^{3}$ and Ming Jin² $^{2^{*}}$
}

\begin{abstract}
Background: To study the morphologic and biochemical changes in the retina and sclera induced by form deprivation high myopia (FDHM) in guinea pigs and explore the possible mechanisms of FDHM formation.

Methods: Forty 3-week-old guinea pigs were randomized into the blank control (Group I, 20 cases) and model groups (20 cases). In the model group, the right eyes of the guinea pigs were sutured for 8 weeks to induce FDHM (Group II) and the left eyes were considered a self-control group (Group III). The refractive errors were measured with retinoscopy. The anterior chamber depth $(A C)$, lens thickness $(L)$, vitreous chamber depth $(V)$ and axial length $(\mathrm{AL})$ were measured using ultrasonometry A. Retinal and scleral morphology and ultrastructural features were observed with light and electron microscopy. The malondialdehyde (MDA) content and superoxide dismutase (SOD) activity in the retina and sclera were detected with a chemical colorimetric assay.

Results: After 8 weeks of stitching, the refractive errors of Group II changed from $(+3.59 \pm 0.33) \mathrm{D}$ to ($7.96 \pm 0.55) D$, and these values were significantly higher than those of Group I (+ 0.89 \pm 0.32$)$ D and Group III $(-0.55 \pm 0.49) \mathrm{D}(P<0.05)$. The vitreous chamber depth $(4.12 \pm 0.13) \mathrm{mm}$ and axial length $(8.93 \pm 0.22) \mathrm{mm}$ of Group II were significantly longer than those of Group I [(3.71 \pm 0.23$) \mathrm{mm}$ and $(7.95 \pm 0.37) \mathrm{mm}$, respectively] and Group III [(3.93 \pm 0.04$) \mathrm{mm}$ and $(8.01 \pm 0.15) \mathrm{mm}$, respectively] $(P<0.05)$. With the prolongation of form deprivation (FD), the retina and scleral tissues showed thinning, the ganglion cell and inner and outer nuclear layers of the retina became decreased, and the arrangement was disordered. In Group II, the SOD activity was significantly lower than that in Group I and Group III; the MDA content was significantly higher than that in Group I and Group III. The differences were statistically significant $(P<0.05)$.

Conclusions: These findings suggested that in the FDHM guinea pigs model, the refractive errors, the vitreous chamber depth, and axial length increased significantly with prolongation of monocular FD time, and morphological structural changes in the retina and sclera were observed. Oxygen free radicals might participate in the formation of FDHM.
\end{abstract}

Keywords: Form deprivation, High myopia, Local retinal regulation, Oxygen free radical, Guinea pig

\footnotetext{
* Correspondence: jinmingyk@163.com

${ }^{2}$ Department of Ophthalmology, China-Japan Friendship Hospital, Yinghua Donglu, Chaoyang District, Beijing 100029, China

Full list of author information is available at the end of the article
}

(c) The Author(s). 2020 Open Access This article is licensed under a Creative Commons Attribution 4.0 International License, which permits use, sharing, adaptation, distribution and reproduction in any medium or format, as long as you give appropriate credit to the original author(s) and the source, provide a link to the Creative Commons licence, and indicate if changes were made. The images or other third party material in this article are included in the article's Creative Commons licence, unless indicated otherwise in a credit line to the material. If material is not included in the article's Creative Commons licence and your intended use is not permitted by statutory regulation or exceeds the permitted use, you will need to obtain permission directly from the copyright holder. To view a copy of this licence, visit http://creativecommons.org/licenses/by/4.0/. The Creative Commons Public Domain Dedication waiver (http://creativecommons.org/publicdomain/zero/1.0/) applies to the data made available in this article, unless otherwise stated in a credit line to the data. 


\section{Background}

Myopia is a global epidemic ametropia caused by a combination of genetic and environmental factors [1]. Worldwide, the number of people with high myopia (HM) is approximately 163 million, accounting for $2.7 \%$ of the total population. It is estimated that by 2050, the number of people with HM will increase to 938 million, accounting for $9.8 \%$ of the total population. The number of people with HM in China is 87 million, accounting for $6.3 \%$ of the total population. It is estimated that by 2050, the number of people with HM will exceed 175 million, accounting for $13 \%$ of the total population [2]. Surveys have shown that the prevalence of HM in Chinese adolescents is $6.69-38.4 \%$; that is, China is a typical country with a high incidence of HM [3, 4]. As myopic refractive errors increase, especially up to HM, the incidence of fundus lesions, risk of blindness and medical costs also increase [5]. Pathological myopia (PM) was reported to be an important cause of global vision loss, and the prevalence of PM is 0.9 to $3.1 \%$. The prevalence of PM associated with visual impairment in European countries is 0.1 to $0.5 \%$, and the prevalence in Asian countries is high, ranging from 0.2 to $1.4 \%$. Studies in China have shown that PM is the most common cause of blindness, accounting for $26.1 \%$ of cases [6]. At present, the occurrence of myopia tends to be higher in younger people and is in a more advanced stage. HM fundus lesions, especially macular degeneration, are the main causes of blindness in East Asian countries [7].

The form deprivation myopia (FDM) theory was proposed in 1977. After Wiesel et al. [8] sutured the eyelids of newborn rhesus monkeys, the sutured eyes caused obvious axial myopia. According to research needs, some scholars have carried out myopia research on the eyes of animals such as tree shrews [9, 10], chickens [11], mice [12], rats [13], and guinea pigs [14]. Studies have confirmed that form deprivation (FD) in young animals leads to abnormal growth of the eye axis and the formation of obvious myopia $[15,16]$. Guinea pigs are widely used in the current research on myopia since the eyeball structure and emmetropization mechanism are similar to those of human myopia. The mechanism of HM formation is very complicated, and local retinal regulation is a focus of research. It has been shown that in myopic eyes, the axial length increases, and vascular changes, such as retinal vascularization diminishing and narrowing, are observed [17]. Shih's research revealed that along with the increase in myopic refractive errors, the ocular pulse amplitude, which is generated by choroidal blood flow, was decreased. The circulatory disturbance was observed in the formation of myopia [18]. Oxidative stress (OS) is not only involved in the development of myopia but is also accompanied by the complications of HM. The elevated level of malondialdehyde (MDA) in the vitreous of myopic subjects strongly suggests retinal lipid peroxidation involvement in the genesis of the human myopic cataracts [19]. OS levels and metabolic activities in the aqueous humour were lower in patients with high myopia than the controls [20]. Simonelli et al. [21] demonstrated that lipid peroxidation might be associated with the pathogenesis of severe myopia. MDA, as the breakdown product of lipid peroxidation, would induce the accumulation of soluble proteins and fragmentation of the membrane structure. Bhatia et al. [22] also stated that OS was related to myopic lens. Compared with that in age-related cataracts, the content of superoxide dismutase (SOD) was lower in myopic patients. Compared with that of healthy controls, the MDA level in plasma was higher in myopia. Shkrebets [23] reported that the antioxidant capacity in tears is weakened in HM patients. To some extent, SOD, as the first line of defence against OS and an important component of the enzymatic antioxidant defence system in the retina, can increase the activity of endogenous peroxide detoxifying activity. Xu Huibi et al. [24] reported that the SOD activity decreased in the retina of myopic eyes in formsense-deprived chicks. However, fewer studies about the activities of total SOD in form deprivation high myopia (FDHM) in guinea pigs have been performed. This study intended to establish a guinea pig model of FDM to simulate HM, observe changes in the retinal and scleral morphology, determine the MDA content in the retina and sclera, and assess the SOD activity. The relationship between oxygen free radicals and the formation of FDHM provides new ideas and a basis for further research on myopia, especially HM.

\section{Methods}

\section{Animal model and grouping}

Forty pigmented guinea pigs at 2 weeks of age weighing $100 \mathrm{~g}$ to $140 \mathrm{~g}$ were obtained from the Beijing Keyu Animal Breeding Center. \{SCXK (Jing) 2017-0002\}. After acclimation for 1 week, the guinea pigs were randomly assigned to two groups: the blank control group (Group I) with 20 guinea pigs and the model group with 20 guinea pigs. The model group was divided again into the FDHM group (Group II, eyelids on their right eyes were stitched for 8 weeks) and the self-controlled group (Group III, left eyes received no intervention). The operation of Group II was performed under anesthesia (intraperitoneal injection with $1 \%$ pentobarbital sodium, 50 $\mathrm{mg} / \mathrm{Kg}$ ). All animals had access to abundant food and water at the Institute of Chinese Materia Medica, China Academy of Chinese Medical Sciences Central Animal Laboratory \{SYXK (Jing) 2016-0013\}, and vitamin-rich feed and fresh vegetables were given to supplement vitamin C. This study was approved by the Ethics Committee of the China-Japan Friendship Hospital (ethics 
review number: 180103) and was conducted in accordance with the Association for Research in Vision and Ophthalmology Statement for the Use of Animals in Ophthalmology and Vision Research and the Declaration of Helsinki. Before the experiment, the anterior segment and fundus of all guinea pig eyes were examined with a slit lamp microscope and an ophthalmoscope, and those with eye diseases were excluded.

\section{Main equipment and reagents}

A strip light inspection mirror was purchased from Suzhou Liuliu Vision Technology Co., Ltd. A lens box was purchased from Danyang Medical Instrument Factory. A type A ophthalmic ultrasound instrument (ODM-1000) was purchased from Tianjin Maida Medical Technology Co., Ltd. Total SOD (KGT001100) and an MDA (KGT004) test kit were purchased from Beijing Benuowei Biotechnology Co., Ltd.

\section{Biological measurements}

All guinea pigs were treated with mydriatic optometry before and after FD for 8 weeks. Before FD, tropicamide eye drops were used to fully enlarge the pupil, and the ciliary muscle was paralyzed. The optometry was performed in a dark room with a band-shaped photoreceptor. Each eye was measured three times to obtain an average value. The astigmatism degree was transformed into half of the count, and this was included in the spherical mirror. Surface anesthesia was performed with $0.4 \%$ oxybuprocaine hydrochloride eye drops. The length of each component of the eyeball was measured with ultrasonometry A. The probe of ultrasonometry A was perpendicular to the cornea and located in the center of the pupil. Meanwhile, the cornea was not pressed. When the pattern was stable and clear, the posterior capsule of the lens and the double peak of the retina were higher than the baseline, and the image and results were recorded. Each eye was repeatedly measured 8 times to obtain an average value. The recorded data included the anterior chamber depth (AC), lens thickness $(\mathrm{L})$, vitreous chamber depth $(\mathrm{V})$ and axial length (AL). Biological measurements of all guinea pigs were performed under anesthesia (intraperitoneal injection with $1 \%$ pentobarbital sodium, $50 \mathrm{mg} / \mathrm{Kg}$ ). To ensure the welfare of the animals, our method of euthanasia followed the AVMA Guidelines for the Euthanasia of Animals.

\section{Specimen preparation for light microscopy}

After FD for 8 weeks, the eyeballs were enucleated after euthanasia (intraperitoneal injection with pentobarbital sodium, $150 \mathrm{mg} / \mathrm{Kg}$ ). Five eyeballs of each group were removed with the optic nerve 1 to $2 \mathrm{~mm}$ long and fixed in $4 \%$ paraformaldehyde (Solarbio, Beijing, China). The eyecups were made by cutting the eyeball along the limbus and removing the anterior segment, and then, the eyecups were fixed again in $4 \%$ paraformaldehyde at $4{ }^{\circ} \mathrm{C}$ for $24 \mathrm{~h}$. After gradient alcohol dehydration, xylene transparency and paraffin machine embedding, the sclera and retina were continuously sectioned along the longitudinal axis. The sections had a thickness of $4 \mu \mathrm{m}$ and were stained with haematoxylin-eosin (HE). A microphotographic system (OLYMPUS BH-2, Japan) was used to observe the histology and morphology of the sclera and retina.

\section{Specimen preparation for electron microscopy}

Five eyeballs in each group were fixed in $2.5 \%$ glutaraldehyde solution (Solarbio, Beijing) at $4{ }^{\circ} \mathrm{C}$ for $72 \mathrm{~h}$. First, the sclera and retina were sliced to a size of $2 \mathrm{~mm} \times 2$ $\mathrm{mm}$ size and washed three times with phosphate buffer (PBS) for 10 min each time. Second, the eyeball samples were fixed in $1 \%$ citric acid for two hours and rinsed twice with double distilled water for $10 \mathrm{~min}$ each time. Third, ethanol acetone was used for stepwise dehydration. Fourth, the samples were infiltrated and embedded with Epon812 epoxy resin. Then, the slice was cut into a $10 \mathrm{~nm}$ sample and double stained with uranyl acetate and lead citrate. Finally, a Hitachi H-600 transmission electron microscope was used to observe the sclera and retina ultrastructure and take photos.

\section{Colorimetric detection of the MDA content and SOD activity}

After FD for 8 weeks, ten guinea pigs in each group were selected, and then, the eyeballs were removed after the same administration of euthanasia described above. After removal of the anterior segment of the eye on an ice cube, the sclera and retinal/choroidal unity were peeled off with a microscopic tweezer and placed into a cryotube. The wet weight was weighed with a precision analytical balance, and double-distilled water was added to generate a homogenate. The homogenate was centrifuged at $3000 \mathrm{r} / \mathrm{min}$ for $5 \mathrm{~min}$, and the supernatant was taken for testing. According to the SOD vitality test kit instructions, we used a 96-well plate to set the sample well and the blank control well. We then added the sample to be tested and other various solutions in turn, and we added the reaction start working solution, mixed it well, and incubated it at $37^{\circ} \mathrm{C}$ for $30 \mathrm{~min}$. We measured the absorbance at $450 \mathrm{~nm}$ and calculated the SOD vitality according to the formula in the instruction manual. Based on the MDA kit standard tube absorbance, we used $0.1 \mathrm{ml}$ as the standard. The standard tube absorbance minus the standard blank tube absorbance was 0.103-0.112. We calculated the MDA content according to the formula in the manual. 
Table 1 Changes of refractive errors at three and 11 weeks of age in each group of guinea pigs

\begin{tabular}{|c|c|c|c|c|c|c|c|}
\hline & \multirow{2}{*}{$\begin{array}{l}\text { Group I } \\
(n=20)\end{array}$} & \multirow{2}{*}{$\begin{array}{l}\text { Group II } \\
(n=20)\end{array}$} & \multirow{2}{*}{$\begin{array}{l}\text { Group III } \\
(n=20)\end{array}$} & \multirow{2}{*}{$\begin{array}{l}P \text { Values among } \\
3 \text { groups }\end{array}$} & \multicolumn{3}{|c|}{$P$ values of post hoc Comparison } \\
\hline & & & & & | vs. || & II vs. III & | vs. ||| \\
\hline Refractive errors, D (3-week-old guinea pigs) & $+3.65 \pm 0.27$ & $+3.59 \pm 0.33$ & $+3.61 \pm 0.29$ & 0.8352 & & & \\
\hline Refractive errors, D (11-week-old guinea pigs) & $+0.89 \pm 0.32$ & $-7.96 \pm 0.55$ & $-5.55 \pm 0.49$ & $<.0001$ & $<.0001$ & $<.0001$ & $<.0001$ \\
\hline
\end{tabular}

Ultrasonometry A measurement results and statistics

\section{Statistical analysis}

SPSS statistics 22.0 software was used to analyse the results. Data are shown as the mean \pm standard deviation $\left({ }^{-} \mathrm{x} \pm \mathrm{s}\right)$. Comparisons between the blank control and model group were performed using independent $t$ tests. Comparisons between Group II and Group III were performed using paired sample $t$ tests. A value of $<0.05$ was considered statistically significant between the groups.

\section{Results}

\section{Changes in the refractive status of the Guinea pig} eyeballs

The guinea pigs were born with hyperopia. The refractive errors of the 3-week-old guinea pigs were approximately $+3.50 \mathrm{D}$. Table 1 shows that there was no significant difference in the refractive errors among the groups before FD $(P>0.05)$. After the animals received FD for 8 weeks in the right eyes, the refractive errors of Group II were significantly increased compared with those of Group I $(P<0.05)$. The refractive errors of Group II were higher than those of Group III, and the differences were statistically significant $(P<0.05)$.

After FD, the vitreous cavity of Group II was deepened, and the axial length of the eye increased. Compared with Group I, the difference was statistically significant $(P<0.01)$. The depth of the vitreous cavity and the axis of the right eye in the guinea pigs in Group III were compared. The length was less than that in Group II, and the difference was also statistically significant $(P=0.000)$. There was no significant difference in the depth of the anterior chamber and the thickness of the lens among the groups before and after FD $(P>0.05$; Table 2).

\section{Observation of the Guinea pig retinas under a light microscope}

Figure 1 showed that the retinal structure of Group I was clear, the thickness of the ganglion cell layer was normal, the monolayer was normally distributed, the nucleus was round, the nucleolus was clear and neatly arranged, there was no cell loss or deformation, and the retinal pigment epithelium (RPE) included visual cells. The outer segment protruded as small protrusions arranged in a brush-like shape and was neat and dense (Fig. 1a). After FD for 8 weeks, the retinas of Group II showed thinning, the ganglion cell and inner and outer nuclear layers were all reduced, the nucleus was small and uneven, and the cells were arranged in a disorderly manner. The microvilli protruding from the RPE layer were shorter and even showed fusion and breakage (Fig. 1b). The retinas of Group III showed only a decrease in ganglion cells, a small nucleus, and clear structures in the remaining layers (Fig. 1c).

Observation of the guinea pig retinas under an electron microscope.

Figure 2 showed that under an electron microscope, the retinal disks of Group I were arranged neatly and tightly (Fig. 2a). Compared with those Group I, the membrane disks of Group II showed swelling and deformation (as shown by the red arrow in Fig. 2b). Figure 3 showed that the nuclear layer of the cell membranes was smooth and completed with uniform chromatin (Fig. 3a). Compared

Table 2 Changes in measurement parameters of ultrasonometry A at three and 11 weeks of age in each group of guinea pigs

\begin{tabular}{|c|c|c|c|c|c|c|c|}
\hline & \multirow{2}{*}{$\begin{array}{l}\text { Group I } \\
(n=20)\end{array}$} & \multirow{2}{*}{$\begin{array}{l}\text { Group II } \\
(n=20)\end{array}$} & \multirow{2}{*}{$\begin{array}{l}\text { Group III } \\
(n=20)\end{array}$} & \multirow{2}{*}{$\begin{array}{l}P \text { Values among } \\
3 \text { groups }\end{array}$} & \multicolumn{3}{|c|}{$P$ values of post hoc Comparison } \\
\hline & & & & & | vs. || & II vs. III & | vs. II| \\
\hline AC, mm (3-week-old guinea pigs) & $1.22 \pm 0.15$ & $1.24 \pm 0.06$ & $1.23 \pm 0.34$ & 0.3216 & NS & NS & NS \\
\hline AC, mm (11-week-old guinea pigs) & $1.31 \pm 0.14$ & $1.39 \pm 0.24$ & $1.31 \pm 0.41$ & 0.2130 & NS & NS & NS \\
\hline L, mm (3-week-old guinea pigs) & $3.05 \pm 0.15$ & $3.05 \pm 0.31$ & $3.03 \pm 0.28$ & 0.1356 & NS & NS & NS \\
\hline L, mm (11-week-old guinea pigs) & $3.11 \pm 0.21$ & $3.14 \pm 0.16$ & $3.12 \pm 0.17$ & 0.2031 & NS & NS & NS \\
\hline VC, mm (3-week-old guinea pigs) & $3.42 \pm 0.13$ & $3.43 \pm 0.24$ & $3.44 \pm 0.16$ & 0.0645 & NS & NS & NS \\
\hline VC, mm (11-week-old guinea pigs) & $3.71 \pm 0.23$ & $4.12 \pm 0.13$ & $3.97 \pm 0.03$ & 0.0046 & 0.0029 & 0.0036 & 0.0014 \\
\hline AL, mm (3-week-old guinea pigs) & $7.26 \pm 0.42$ & $7.27 \pm 0.16$ & $7.27 \pm 0.62$ & 0.1124 & NS & NS & NS \\
\hline AL, mm (11-week-old guinea pigs) & $7.95 \pm 0.37$ & $8.93 \pm 0.22$ & $8.26 \pm 0.15$ & 0.0102 & 0.0013 & 0.0002 & 0.0023 \\
\hline
\end{tabular}



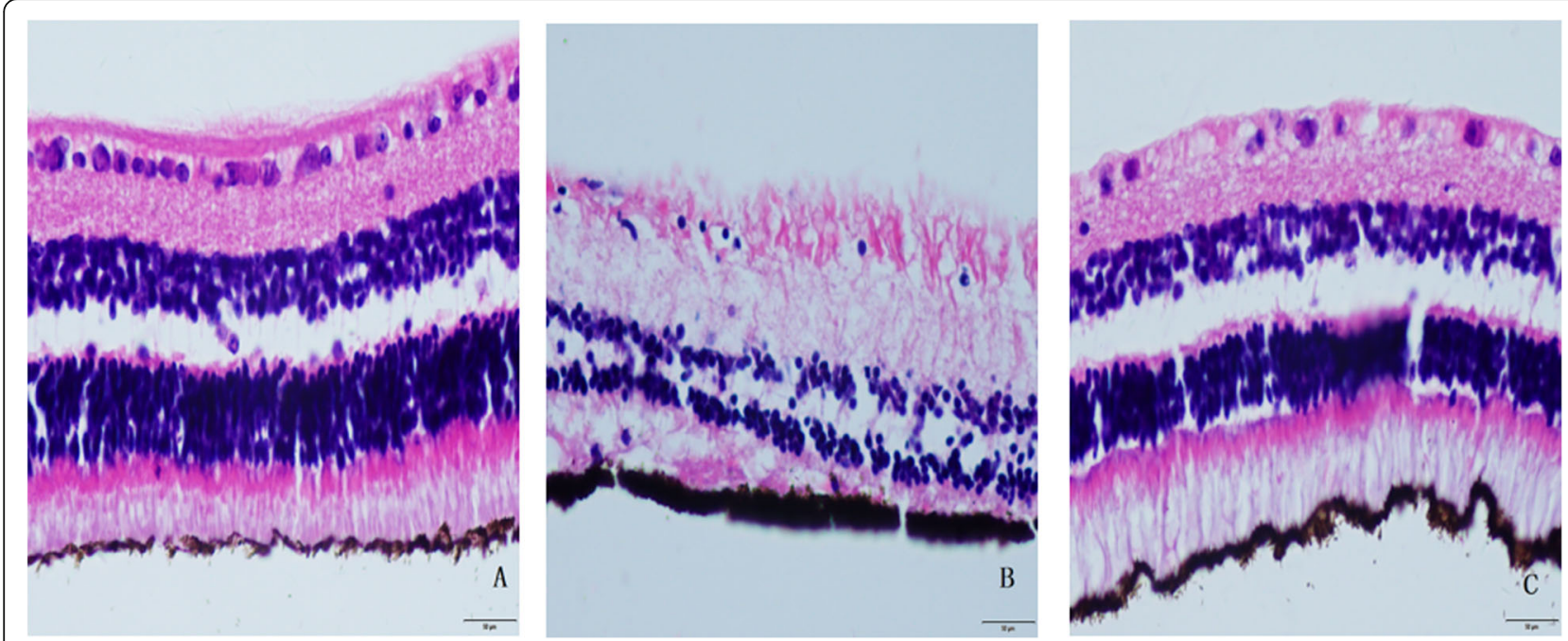

Fig. 1 Observation of guinea pig retinas under light microscope (HEX 400)

with Group I, Group II showed irregular contraction of the inner and outer nuclear layers and RPE cell membrane, irregular accumulation of nuclear chromatin, mitochondrial swelling, deformation and vacuolization (as shown by the red arrow in Fig. 3b). The pathological damage to the retinal membrane disk and inner nuclear layers in Group III was weaker than that in Group II (Fig. 2c, Fig. 3c).

\section{Observation of the Guinea pig sclera under a light microscope}

Figure 4 showed that the scleral thickness of Group I was normal. The fibroblasts were stained blue-purple and were fusiform or oblong, the extracellular matrix was pink, the collagen fibres were neatly arranged, and the diameters were uniform (Fig. 4a). The sclera of the guinea pigs in Group II showed obvious thinning; the fibroblast cell nuclei were distorted; the collagen fibres were sparsely distributed; the diameter was obviously reduced; the arrangement was disordered, twisted, broken, and separated; the interfibre space was increased; and the extracellular matrix was increased (Fig. 4b). The scleral thickness of Group III showed slight thinning, but the morphology was not significantly abnormal (Fig. 4c).

\section{Observation of the Guinea pig sclera under an electron microscope}

Figure 5 showed that the scleral tissue was composed of fibroblasts and collagen bundles parallel to the wall of the eyeball. The collagen fibres constitute the framework of the scleral tissue. The cross-sectional diameter of the collagen fibres was observed. There was no significant difference between the sclera of Group I and Group III. Compared with those of the two groups, the diameter of the FDHM was significantly reduced, and the fibre density was decreased in Group II.

The MDA content and SOD activity in the retinal/ choroidal unity and sclera of the guinea pigs.
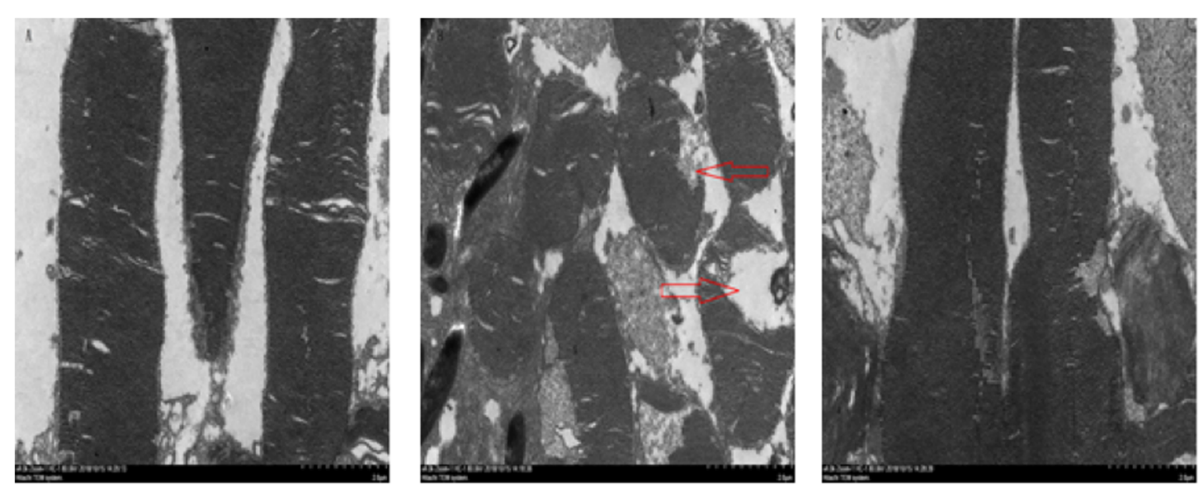

Fig. 2 Observation of guinea pig retinal membrane disk under electron microscopic $(\times 4000)$ 

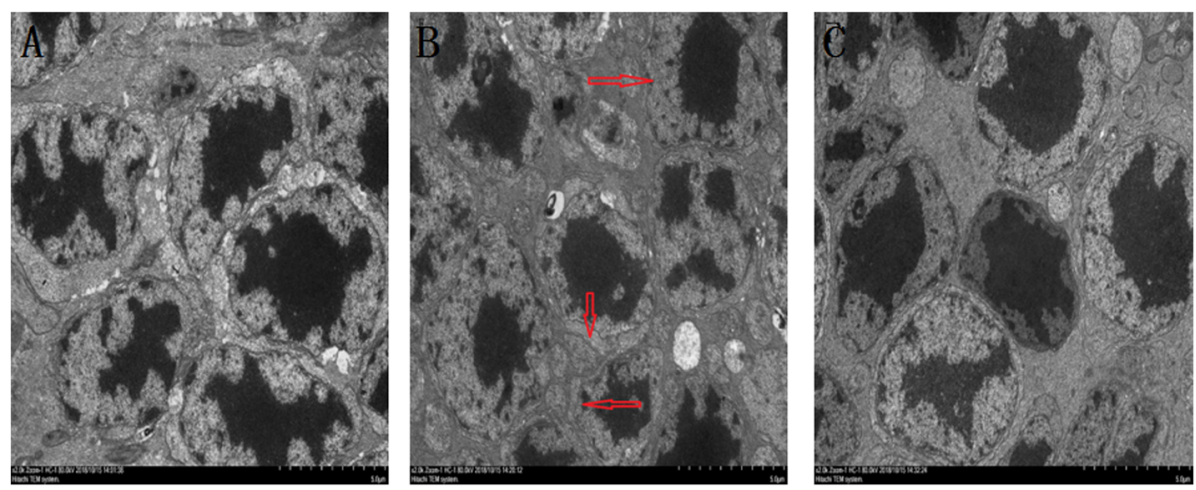

Fig. 3 Observation of guinea pig retinal inner nuclear layers under electron microscopic $(\times 4000)$

The statistical results showed that the activity of SOD and MDA, the main products of lipid peroxide, had an opposite trend. That is, under normal circumstances, the SOD of the retinal/choroidal unity and sclera remained high in the normal group, while MDA was at a low level. However, after FD, compared with that in Group I, the content of SOD in the retinal/choroidal unity and sclera of the guinea pigs in Group II decreased, while the content of MDA increased $(P<0.01)$. There was no significant difference compared with Group III $(P>0.05$; Tables 3, 4).

\section{Discussion}

Since the refractive status and orthotopic mechanism of guinea pigs are similar to those of humans, guinea pigs are born with hyperopia. In 3 weeks, the axial length of the guinea pigs grew rapidly, and the refractive errors decreased. The refractive state of 11week-old guinea pigs was stabilized in the mild hyperopic eye. The FDM model has been widely used in experimental research on myopia [25, 26]. Studies have shown that guinea pigs have the characteristic of high sensitivity to FD and become ideal animal models of experimental myopia [27]. In this study, 3- week-old guinea pigs were selected as a myopic animal model. At this time, guinea pigs were in a critical period of visual development and were sensitive to the model manipulations. By prolonging the time of FD, we aimed to cause high myopia [28]. The retina is a tissue with a high oxygen demand, strong metabolism and active redox reaction. Under physiological conditions, intraocular tissues, such as the retina, are continuously stimulated by external light to cause photooxidation, which promotes the formation of oxygen free radicals. Furthermore, effective antioxidants, such as SOD, in the cells can promptly scavenge oxygen free radicals. The formation and degradation are in a dynamic equilibrium, which provides protection for tissues such as the retina and sclera. Under pathological conditions, excessive generation of oxygen free radicals or an insufficient antioxidant capacity of the body can trigger lipid peroxidation, and the main metabolite, MDA, causes damage to cells and tissues. OS can lead to retinal damage under hypoxic circumstances $[29,30]$. This could be used to explain the relationship between OS and FDHM since hypoxic situations would exist chronically. The MDA content reflects the degree of attack on oxygen by oxidative

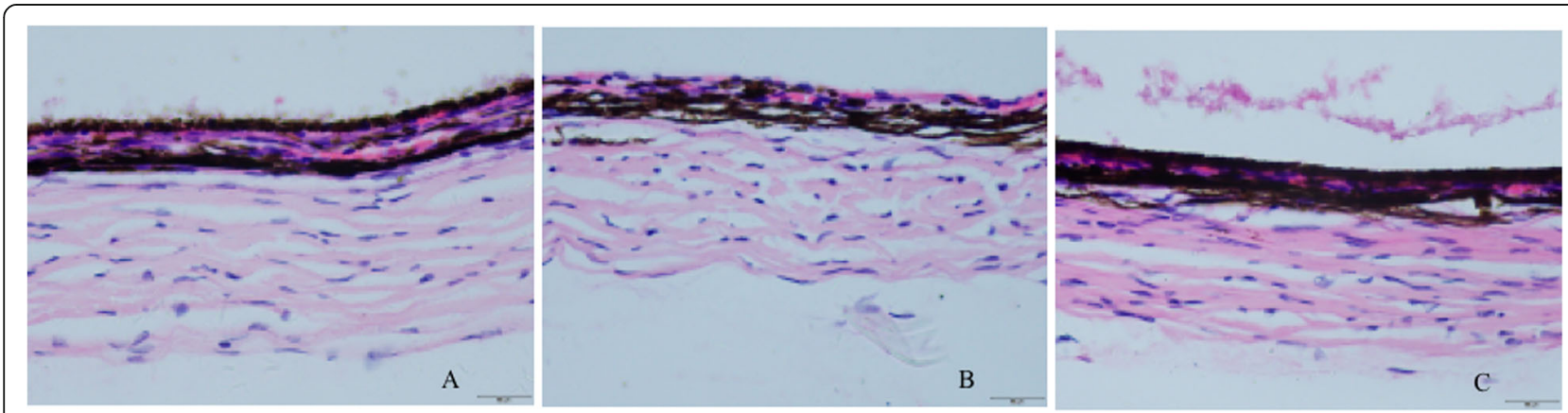

Fig. 4 Observation of guinea pig sclera under a light microscope (HEx 400) 

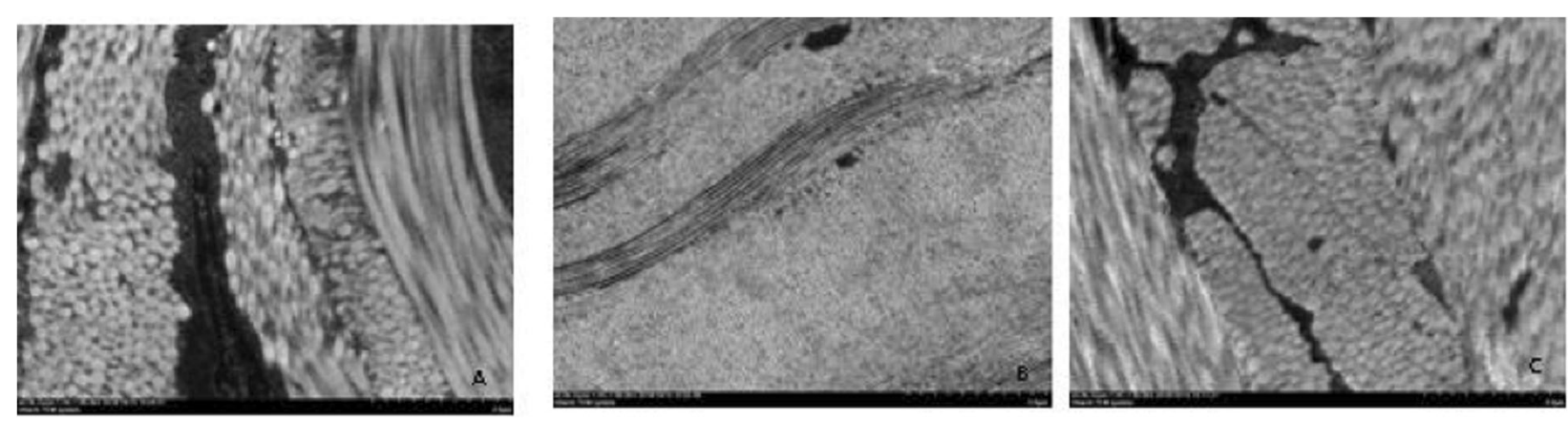

Fig. 5 Observation of guinea pig sclera under an electron microscope $(\times 4000)$

cells. SOD is an important antioxidant enzyme in the body, and its activity reflects the body's ability to scavenge oxygen free radicals [31, 32].

The results of this study showed that after 8 weeks of FD due to guinea pig eyelid suture, the myopic refractive errors decreased, with the highest value at $8.00 \mathrm{D}$ refraction, and the biometric data determined by Ultrasonometry A increased; the vitreous cavity was elongated and the axial length became longer. Compared with Group I, the difference was statistically significant $(P<0.01)$, which indicated that the high myopia model was successful. The results are trustworthy since the refractive errors were examined by a skilled optometrist and repeated three times to obtain the average value. The guinea pig model was first presented by McFadden and Wallman at ARVO in 1995. It has been reported that guinea pigs could develop deprivation myopia after a short period of time usually a few days [33]. The guinea pig model is the most common animal model for myopia in Asian laboratories [16]. As shown in a myopic animal model, there exists an approximately 3,00 D difference between the model group and the self-controlled group after occlusion for 14 days [34]. There may be species differences between guinea pigs and tree shrews. The specific mechanism for these differences needs further investigation. There was no significant difference in the biochemical parameters between Group II and the Group III (both $P>0.05$ ). Deprivation in Group II did not interfere with the natural development of the contralateral eye, which is

Table 3 Content of SOD and MDA in retinal/choroidal unity of guinea pigs $(n=5,-x \pm s)$

\begin{tabular}{|c|c|c|}
\hline Group & $\mathrm{SOD}(\mu \mathrm{g} / \mathrm{g})$ & MDA $(\mu \mathrm{g} / \mathrm{l})$ \\
\hline I & $230.01 \pm 14.97$ & $4.33 \pm 0.43$ \\
\hline$\|$ & $173.35 \pm 29.69^{\mathrm{ab}}$ & $9.23 \pm 0.85^{\mathrm{ab}}$ \\
\hline III & $187.73 \pm 18.31$ & $8.70 \pm 1.59$ \\
\hline
\end{tabular}

consistent with the findings of other researchers, such as Zhao [35]. Yang et al. [36] detected retinal metabolic changes in guinea pigs induced by form deprivation myopia. Although these researchers did not directly measure the SOD and MDA levels, the results they reported represented the retinal metabolite levels. That is, no statistically significant differences were revealed between the FD and selfcontrolled eyes. In our study, the SOD and MDA contents decreased and increased, respectively, compared with those of Group I. There are several potential possibilities to account for the mismatch with the refraction and biometric parameters. Myopia development is a time-dependent process. Thus, it is necessary to measure biochemical parameters at more time-points in further studies. We expect that these differences in biometric parameters would be significant if the sample size was larger.

\section{Conclusions}

In summary, this experiment produced a HM status in the guinea pigs FD for 8 weeks. We observed retinal and scleral morphology, refractive errors, vitreous cavity depth, axial length change and SOD and MDA expression. Disorders in the oxygen free radical level may be involved in the development of FDHM. The results of this study provide new ideas for the pathogenesis and prevention of HM. However, the specific mechanism of action is not fully understood, and further research is needed.

Table 4 Content of SOD and MDA content in sclera of guinea pigs $(n=5,-x \pm s)$

\begin{tabular}{lll}
\hline Group & SOD $(\mu \mathrm{g} / \mathrm{g})$ & MDA $(\mu \mathrm{g} / \mathrm{l})$ \\
\hline $\mathrm{I}$ & $261.60 \pm 2.30$ & $0.44 \pm 2.37$ \\
$\|$ & $197.60 \pm 2.40^{\mathrm{ab}}$ & $1.99 \pm 1.73^{\mathrm{ab}}$ \\
III & $227.99 \pm 4.54$ & $1.01 \pm 2.40$ \\
\hline Compared with Group I, $^{\text {a }} P<0.01$, compared with Group III, $^{\mathrm{b}} P>0.05$
\end{tabular}




\section{Abbreviations}

HM: High myopia; PM: Pathological myopia; FDM: Form deprivation myopia; FD: Form deprivation; MDA: Malondialdehyde; SOD: Superoxide dismutase; FDHM: Form deprivation high myopia; AC: Anterior chamber depth; L: Lens thickness; V: Vitreous chamber depth; AL: Axial length; HE: Haematoxylineosin; PBS: Phosphate buffer; RPE: Retinal pigment epithelium

\section{Acknowledgements}

Not applicable.

\section{Authors' contributions}

YX Z and MJ designed the study, analyzed the data and wrote the manuscript. $Y X Z, Y D, J R Z$, and $M Q$ J performed the animal study. $Y L Q$ and $\Pi \Pi D$ revised and made suggestions to the manuscript. All authors read and approved the final manuscript.

\section{Funding}

This study was supported by the National Natural Science Foundation of China (No. 81574029). The funders had no role in the design or conduct of this study or in writing the manuscript. In order to improve the English writing of this manuscript, the funder helped us seek a native English speaker who works on myopia research from English-editing company ( $\mathrm{Na}$ ture Research Editing Service).

\section{Availability of data and materials}

The datasets used and/or analysed during the current study are available from the corresponding author on reasonable request at any time.

\section{Ethics approval and consent to participate}

This study was approved by the Ethics Committee of the China-Japan Friendship Hospital (ethics review number: 180103) and was conducted in accordance with the Association for Research in Vision and Ophthalmology Statement for the Use of Animals in Ophthalmology and Vision Research and the Declaration of Helsinki.

\section{Consent for publication}

Not applicable.

\section{Competing interests}

The authors declare that they have no competing interests.

\section{Author details}

'Department of Graduate School, Beijing University of Chinese Medicine, No.11, North 3rd Ring East Road, Chaoyang District, Beijing 100029, China. ${ }^{2}$ Department of Ophthalmology, China-Japan Friendship Hospital, Yinghua Donglu, Chaoyang District, Beijing 100029, China. Institute of Clinical Medical Sciences, China-Japan Friendship Hospital, Yinghua Donglu, Chaoyang District, Beijing 100029, China.

\section{Received: 12 April 2019 Accepted: 9 March 2020}

\section{Published online: 16 March 2020}

\section{References}

1. Jones D, Luensmann D. The prevalence and impact of high myopia. Eye Contact Lens. 2012;38:188-96. https:/doi.org/10.1097/ICL.0b013e31824ccbc3.

2. Holden BA, Fricke TR, Wilson DA, Jong M, Naidoo KS, Sankaridurg P, et al. Global prevalence of myopia and high myopia and temporal trends from 2000 through 2050. Ophthalmology. 2016;123:1036-42. https://doi.org/10. 1016/j.ophtha.2016.01.006.

3. Li Y, Liu J, Qi P. The increasing prevalence of myopia in junior high school students in the Haidian district of Beijing, China: a 10-year population-based survey. BMC Ophthalmol. 2017;17:88. https://doi.org/10.1186/s12886-017-0483-6.

4. Sun J, Zhou J, Zhao P, Lian J, Zhu H, Zhou Y, et al. High prevalence of myopia and high myopia in 5060 Chinese university students in Shanghai. Invest Ophthalmol Vis Sci. 2012;53:7504-9. https://doi.org/10.1167/iovs.11-8343.

5. Cho BJ, Shin JY, Yu HG. Complications of pathologic myopia. Eye Contact Lens. 2016;42:9-15. https://doi.org/10.1097/ICL.0000000000000223.

6. Wong TY, Ferreira A, Hughes R, Carter G, Mitchell P. Epidemiology and disease burden of pathologic myopia and myopic choroidal neovascularization: an evidence-based systematic review. Am J Ophthalmol. 2014;157:9-25. https://doi.org/10.1016/j.ajo.2013.08.010.
7. Iwase A, Araie M, Tomidokoro A, Yamamoto T, Shimizu H, Kitazawa Y, et al. Prevalence and causes of low vision and blindness in a Japanese adult population. Ophthalmology. 2006;113:1354-62. https://doi.org/10.1016/j. ophtha.2006.04.022.

8. Wiesel TN, Raviola E. Myopia and eye enlargement after neonatal lid fusion in monkeys. Nature. 1977;266:66-8. https://doi.org/10.1038/266066a0.

9. Sherman SM, Norton TT, Casagrande VA. Myopia in the lid-sutured tree shrew (Tupaia glis). Brain Res. 1977;124:154-7. https://doi.org/10.1016/00068993(77)90872-1.

10. Marsh-tootle WL, Norton TT. Refractive and structural measures of lid-suture myopia in tree shrew. Invest Ophthalmol Vis Sci. 1989;30:2245-57.

11. Morgan I, Kucharski R, Krongkaew N, Firth SI, Megaw P, Maleszka R. Screening for differential gene expression during the development of formdeprivation myopia in the chicken. Optom Vis Sci. 2004;81:148-55. https:// doi.org/10.1097/00006324-200402000-00013.

12. Yu Y, Li M, Guan HJ, Chen H. Expression and role of Egr-1 gene in retina of flicker light-induced eyes in mice. Chin J of Exp Ophthalmol. 2015;33:621-6. https://doi.org/10.3760/cma.j.issn.2095-0160.2015.07.011.

13. Wang $X, X u$ G, Fan J, Zhang M. Mechanical stretching induces matrix metalloproteinase-2 expression in rat retinal glial (Müller) cells. Neuroreport. 2013;24:224-8. https://doi.org/10.1097/WNR.0b013e32835eb9d1.

14. Wang KK, Metlapally R, Wildsoet CF. Expression profile of the integrin receptor subunits in the Guinea pig sclera. Curr Eye Res. 2017;42:857-63. https://doi.org/10.1080/02713683.2016.1262045.

15. Francisco BM, Salvador M, Amparo N. Oxidative stress in myopia. Oxidative Med Cell Longev. 2015;2015:750637. https://doi.org/10.1155/2015/750637.

16. Schaeffel F, Feldkaemper M. Animal models in myopia research. Clin Exp Optom. 2015;98:507-17. https://doi.org/10.1111/cxo.12312.

17. Avetisov ES, Savitskaya NF. Some features of ocular microcirculation in myopia. Ann Ophthalmol. 1977;9:1261-4.

18. Shih YF, Horng $\mathrm{HH}_{\text {, Yang }} \mathrm{CH}$, Lin LL, Peng Y, Hung PT. Ocular pulse amplitude in myopia. J Ocul Pharmacol. 1991;7:83-7. https://doi.org/10. 1089/jop.1991.7.83.

19. Micelli-Ferrari T, Vendemiale G, Grattagliano I, Boscia F, Arnese L, Altomare E, et al. Role of lipid peroxidation in the pathogenesis of myopic and senile cataract. Br J Ophthalmol. 1996;80:840-3. https:/doi.org/10.1136/bjo.80.9.840.

20. Kim EB, Kim HK, Hyon JY, Wee WR, Shin YJ. Oxidative stress levels in aqueous humor from high myopic patients. Korean J Ophthalmol. 2016;30: 172-9. https://doi.org/10.3341/kjo.2016.30.3.172.

21. Simonelli F, Nesti A, Pensa M, Romano L, Savastano S, Rinaldi E, et al. Lipid peroxidation and human cataractogenesis in diabetes and severe myopia. Exp Eye Res. 1989:49:181-7. https://doi.org/10.1016/0014-4835(89)90088-2.

22. Bhatia RP, Rai R, Rao GR. Role of malondialdehyde and superoxide dismutase in cataractogenesis. Ann Ophthalmol (Skokie). 2006;38:103-6. https://doi.org/10.1385/ao:38:2:103.

23. Shkrebets GV. Biochemical parameters and prediction of the development of glaucoma in patients with progressive myopia. Vestn oftalmol. 2010;126:17-9.

24. Huibi X, Kaixun H, Qiuhua G, Yushan Z, Xiuxian H. Prevention of axial elongation myopia by the trace element zinc. Biol Trace Elem Res. 2001;79: 39-47. https://doi.org/10.1385/BTER:79:1:39.

25. Tsubota K. Anti-aging approach for ocular disorders: from dry eye to retinitis pigmentosa and myopia. Nippon Ganka Gakkai Zasshi. 2017;121:232-48.

26. Srinivasalu N, McFadden SA, Medcalf C, Fuchs L, Chung J, Philip G, et al. Gene expression and pathways underlying form deprivation myopia in the Guinea pig sclera. Invest Ophthalmol Vis Sci. 2018;59:1425-34. https://doi. org/10.1167/iovs.16-21278.

27. Xiao H, Fan ZY, Tian XD, Xu YC. Comparison of form-deprived myopia and lens-induced myopia in Guinea pigs. Int J Ophthalmol. 2014;7:245-50. https://doi.org/10.3980/j.issn.2222-3959.2014.02.10.

28. Ren Y, Xie R, Zhou X, Pan M, Lu F. Spontaneous high myopia in one eye will affect the development of form deprivation myopia in the fellow eye. Curr Eye Res. 2011;36:513-21. https://doi.org/10.3109/02713683.2011.568660.

29. Bhatt L, Groeger G, McDermott K, Cotter TG. Rod and cone photoreceptor cells produce ROS in response to stress in a live retinal explant system. Mol Vis. 2010;16:283-93.

30. Li SY, Fu Z, Lo AC. Hypoxia-induced oxidative stress in ischemic retinopathy. Oxidative Med Cell Longev. 2012;2012:426769. https://doi.org/10.1155/2012/426769.

31. Kresyun NV, Godlevskii LS. Superoxide dismutase and catalase activities in the retina during experimental diabetes and electric stimulation of the paleocerebellar cortex [J]. Bull Exp Biol Med. 2014;158:206-8. https://doi.org/ 10.1007/s10517-014-2723-6. 
32. Park DH, Shin JP, Kim IT. Association of plasma malondialdehyde with ARMS2 genetic variants and phenotypes in polypoidal choroidal vasculopathy and age-related macular degeneration. Retina. 2014;34:116776. https://doi.org/10.1097//AE.0000000000000047.

33. Howlett MH, MCFadden SA. Spectacle lens compensation in the pigmented Guinea pig. Vis Res. 2009;49:219-27. https://doi.org/10.1016/j.visres.2008.10.008.

34. Mao JF, Liu SZ. Mechanism of the DL-alpha-aminoadipic acid inhibitory effect on form-deprived myopia in Guinea pig. Int J Ophthalmol. 2013;6:1922. https://doi.org/10.3980/j.issn.2222-3959.2013.01.04.

35. Zhao $\mathrm{HL}$, Wang RQ, Wu MQ, Jiang J. Dynamic changes of ocular biometric parameters: a modified form-deprivation myopia model of young Guinea pigs. Int J Ophthalmol. 2011;4:484-8. https://doi.org/10.3980/j.issn.2222-3959.2011.05.05.

36. Yang J, Reinach PS, Zhang S, Pan M, Sun W, Liu B, et al. Changes in retinal metabolic profiles associated with form deprivation myopia development in Guinea pigs. Sci Rep. 2017;7:2777. https://doi.org/10.1038/s41598-017-03075-3.

\section{Publisher's Note}

Springer Nature remains neutral with regard to jurisdictional claims in published maps and institutional affiliations.

Ready to submit your research? Choose BMC and benefit from:

- fast, convenient online submission

- thorough peer review by experienced researchers in your field

- rapid publication on acceptance

- support for research data, including large and complex data types

- gold Open Access which fosters wider collaboration and increased citations

- maximum visibility for your research: over $100 \mathrm{M}$ website views per year

At BMC, research is always in progress.

Learn more biomedcentral.com/submissions 